\title{
Correction to: Suborganellar Localization of Mitochondrial Proteins and Transcripts in Human Cells
}

\section{Anna Smirnova, Ludovic Richert, Alexandre Smirnov, Yves Mély, and Ivan Tarassov}

\section{Correction to:}

Chapter 11 in: Volkmar Weissig and Marvin Edeas (ed.), Mitochondrial Medicine:

Volume 3: Manipulating Mitochondria and Disease-Specific Approaches,

Methods in Molecular Biology, vol. 2277,

https://doi.org/10.1007/978-1-0716-1270-5

In the original version of chapter 11 , the author names were printed backwards/incorrectly. The chapter author names are updated now in this revised version of the chapter to "Anna Smirnova, Ludovic Richert, Alexandre Smirnov, Yves Mély, and Ivan Tarassov”. 